\title{
Article
}

Subscriber access provided by GEOMAR Kiel

\section{A portable and autonomous mass spectrometric system for on-site environmental gas analysis}

\author{
Matthias S. Brennwald, Mark Schmidt, Julian Oser, and Rolf Kipfer
}

Environ. Sci. Technol., Just Accepted Manuscript • DOI: 10.1021/acs.est.6b03669 • Publication Date (Web): 19 Nov 2016

Downloaded from http://pubs.acs.org on November 29, 2016

\section{Just Accepted}

"Just Accepted" manuscripts have been peer-reviewed and accepted for publication. They are posted online prior to technical editing, formatting for publication and author proofing. The American Chemical Society provides "Just Accepted" as a free service to the research community to expedite the dissemination of scientific material as soon as possible after acceptance. "Just Accepted" manuscripts appear in full in PDF format accompanied by an HTML abstract. "Just Accepted" manuscripts have been fully peer reviewed, but should not be considered the official version of record. They are accessible to all readers and citable by the Digital Object Identifier (DOIß). "Just Accepted" is an optional service offered to authors. Therefore, the "Just Accepted" Web site may not include all articles that will be published in the journal. After a manuscript is technically edited and formatted, it will be removed from the "Just Accepted" Web site and published as an ASAP article. Note that technical editing may introduce minor changes to the manuscript text and/or graphics which could affect content, and all legal disclaimers and ethical guidelines that apply to the journal pertain. ACS cannot be held responsible for errors or consequences arising from the use of information contained in these "Just Accepted" manuscripts. 


\title{
A portable and autonomous mass spectrometric system for on-site environmental gas analysis
}

\author{
Matthias S. Brennwald, ${ }^{* 1}$ Mark Schmidt, ${ }^{2}$ Julian Oser, ${ }^{1}$ and Rolf Kipfer $^{1,3}$ \\ 1 Eawag, Swiss Federal Institute of Aquatic Science and Technology, Dep. Water Resources and \\ Drinking Water, Dübendorf, Switzerland \\ 2 GEOMAR Helmholtz Centre for Ocean Research Kiel, Wischhofstr. 1-3, 24148 Kiel, Germany \\ 3 Institute for Geochemistry and Petrology, ETH Zurich, Switzerland \\ E-mail: matthias.brennwald@eawag.ch
}

Revison of ES\&T manuscript ES-2016-03669r

November 7, 2016

Corresponding author phone: +4158765 5305 


\section{TOC Art}

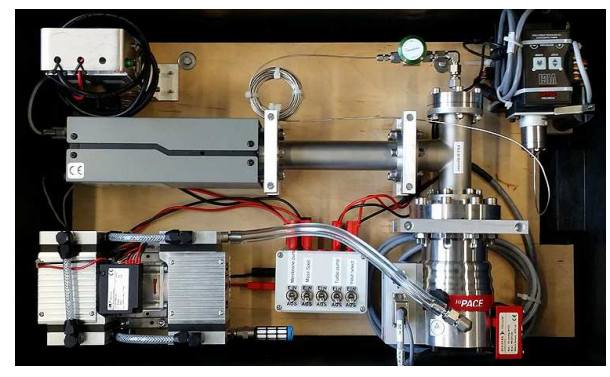




\begin{abstract}
We developed a portable mass spectrometric system ("miniRuedi”) for quantificaton of the partial pressures of $\mathrm{He}, \mathrm{Ne}$ (in dry gas), $\mathrm{Ar}, \mathrm{Kr}, \mathrm{N}_{2}, \mathrm{O}_{2}, \mathrm{CO}_{2}$ and $\mathrm{CH}_{4}$ in gaseous and aqueous matrices in environmental systems with an analytical uncertainty of 1-3\%. The miniRuedi does not require any purification or other preparation of the sampled gases and therefore allows maintenance-free and autonomous operation. The apparatus is most suitable for on-site gas analysis during field work and at remote locations due to its small size $(60 \mathrm{~cm} \times 40 \mathrm{~cm} \times 14 \mathrm{~cm})$, low weight $(13 \mathrm{~kg})$, and low power consumption $(50 \mathrm{~W})$. The gases are continuously sampled and transferred through a capillary pressure reduction system into a vacuum chamber, where they are analysed using a quadrupole mass spectrometer with a time resolution of $\lesssim 1 \mathrm{~min}$. The low gas consumption rate $(<0.1 \mathrm{ml} / \mathrm{min})$ minimises interference with the natural mass balance of gases in environmental systems, and allows the unbiased quantification of dissolved-gas concentrations in water by gas/water equilibration using membrane contractors (gas-equilibrium membrane-inlet mass spectrometry, GE-MIMS). The performance of the miniRuedi is demonstrated in laboratory and field tests, and its utility is illustrated in field applications related to soil-gas formation, lake/atmosphere gas exchange, and seafloor gas emanations.
\end{abstract}




\section{Introduction}

The abundances of gas species in environmental systems are controlled by numerous physical, chemical and biological processes and conditions. Gases are therefore highly useful proxies to study the dynamics of environmental processes and can be of great utility to study the interplay of these processes. In particular, chemically inert gases (noble gases; $\mathrm{He}, \mathrm{Ne}, \mathrm{Ar}, \mathrm{Kr}, \mathrm{Xe}$ ) were successfully used to study and quantify physical transport and mixing of fluids as well as the exchange between gas and water ${ }^{1-27}$ or biofluids. ${ }^{28,29}$ Such quantitative information on the physical processes controlling the dynamics of gases in environmental systems is required to quantify and interpret the turnover and the fate of biogeochemically active species (e.g., $\mathrm{O}_{2}, \mathrm{CO}_{2}, \mathrm{CH}_{4}, \mathrm{~N}_{x} \mathrm{O}_{x}$ ) in terms of chemical and biological processes $5,21,30-35$

The dynamics of gases and the associated processes in environmental systems are often not accessible from "snapshot data" obtained from single samples reflecting the conditions of a system at a unique point in time. In order to capture the complete evolution of the gas species of interest, data series with sufficiently high temporal and spatial resolution are required. Careful optimisation of the sampling strategy in terms of sampling frequency and locations is therefore of utmost importance, but is often very challenging due to the lack of prior knowledge of the gas dynamics within a given system.

The currently applied methods for environmental gas analyses are usually targeted at a single gas species or limited set of gases, and are often based on expensive and highly specialised instruments and techniques for sampling and subsequent laboratory based quantification. ${ }^{36-42}$ Acquiring data sets comprising a sufficiently complete suite of both inert and active gas species at the required spatial and temporal resolutions therefore poses numerous practical limitations related to field-work logistics, access to specialised laboratories and data turnaround time that often prevent acquisition of suitable data sets.

The way forward to overcome these technical and logistical limitations is to simultaneously analyse a sufficiently complete suite of inert and biogeochemically active gas species at the required temporal and spatial resolution directly in the field. On-site and real-time availability of 
such data avoids the limitations involved with sampling, transport and analysis and would thus considerably improve the quality and utility of the recorded data during fieldwork. For this purpose, membrane-inlet mass-spectrometric (MIMS) systems ${ }^{43,44}$ were developed with the aim to reduce their complexity and size. ${ }^{42,45-48}$ However, these MIMS are targeted at limited sets of gas species dissolved in water samples only, and are not suitable for unattended long-term operation in the field, because their gas inlet system is designed for manual sample inlet or requires frequent maintenance of gas-purifying devices. In addition, these instruments rely on a gas-permeable membrane to separate the water sample at atmospheric pressure from the vacuum in the MS. The rates by which the gas species diffuse from the bulk water across the membrane and into the vacuum of the MS depend on temperature, water flow along the membrane surface, membrane ageing and fouling, etc. It is notoriously difficult to achieve tight control over these operational parameters and cumbersome to handle water standards with well-known dissolved gas concentrations during fieldwork. Reliable and accurate calibration and application of such MIMS instruments is therefore challenging.

The recently developed gas-equilibrium MIMS (GE-MIMS) method ${ }^{49-51}$ avoids some of the limitations of previous MIMS designs by establishing a solubility equilibrium between the sampled water and a gas phase separated by a gas-permeable membrane. The advantage of the GE-MIMS method is that the gas/water partitioning is hardly affected by the poorly constrained dynamics of the gas-transfer across the membrane, because the partitioning operates at solubility equilibrium. Reliable on-site calibration of such a gas/water equilibration system is therefore straight-forward, and ambient air can be conveniently used as a standard gas for calibration of the partial pressures of the noble gases, $\mathrm{N}_{2}$, and $\mathrm{O}_{2}$.

For GE-MIMS analysis, a small fraction of the equilibrated gas phase is continuously transferred through a pressure reducing system into the MS vacuum, where the gases are analysed. Recent GE-MIMS instruments for analysis of $\mathrm{O}_{2} / \mathrm{Ar} \operatorname{ratios}^{50}$ or $\mathrm{Ne} / \mathrm{Ar}, \mathrm{Ne} / \mathrm{Kr}$, and $\mathrm{Ne} / \mathrm{Xe}$ ratios ${ }^{51}$ in seawater used very low gas transfer rates $\left(\lesssim 0.02 \mathrm{~cm}_{\mathrm{STP}}^{3} / \mathrm{min}, \mathrm{STP}\right.$ : standard temperature and pressure, $T=0{ }^{\circ} \mathrm{C}, P=1013.25 \mathrm{mbar}$ ) to avoid deviation from the gas/water equilibrium in the 
membrane contactor. In contrast, a modified atmospheric-pressure gas analyser targeted for GEMIMS analysis of absolute $\mathrm{He}, \mathrm{Ar}, \mathrm{Kr}, \mathrm{N}_{2}, \mathrm{O}_{2}, \mathrm{CO}_{2}$, and $\mathrm{CH}_{4}$ concentrations ("Ruedi") ${ }^{49}$ operates at a much higher gas removal rate from the membrane contactor $\left(2 \mathrm{~cm}_{\mathrm{STP}}^{3} / \mathrm{min}\right)$. However, this gas depletion biases the partial pressures relative to the assumed gas/water equilibrium in the membrane contactor. While both approaches have illustrated the great potential of continuous analysis of selected gas species, ${ }^{30,32,34,35,52,53}$ the remaining analytical limitations of these instruments (limited sets of gas species, lack of absolute partial pressure analysis) and their bulkiness and high power consumption (several hundred watts) prevented widespread use in diverse environmental research applications in the field.

Here we present a simple, compact, and portable mass spectrometric system with low sample gas consumption ("miniRuedi"). The miniRuedi expands considerably beyond the capabilities of currently available instruments and methods for environmental gas analysis. The system allows quasi-continuous and on-site analysis of the partial pressures of a wide range of environmental gas species at environmental concentrations ( $\mathrm{He}, \mathrm{Ne}$ (in dry gas), $\mathrm{Ar}, \mathrm{Kr}, \mathrm{N}_{2}, \mathrm{O}_{2}, \mathrm{CO}_{2}$ and $\mathrm{CH}_{4}$ ) and is most suitable for absolute analysis of dissolved gas concentrations in aqueous matrices using the GE-MIMS method. The system does not rely on any gas purification or sample preparation units, which makes it robust and maintenance-free and thus enables autonomous long-term operation in the field. The miniRuedi is built using off-the-shelf parts only. The instrument is portable $(60 \mathrm{~cm} \times 40 \mathrm{~cm} \times 14 \mathrm{~cm}, 13 \mathrm{~kg})$ and consumes only $50 \mathrm{~W}$ electrical power, which allows straight-forward deployment and operation at remote locations using batteries, solar panels or other off-grid electricity sources. Most importantly, the instrument consumes very little sample gas $\left(0.06 \mathrm{~cm}_{\mathrm{STP}}^{3} / \mathrm{min}\right)$, which is required for unbiased GE-MIMS measurements of absolute partial pressures, and greatly reduces the interference of on-line gas analysis with the natural dynamics and mass balance of the gases in an environmental system.

The utility of the miniRuedi for environmental research is demonstrated in three field-application examples related to soil-gas formation, lake/atmosphere gas exchange, and seafloor gas emanations. 


\section{Experimental Section}

The setup of the miniRuedi system is illustrated in Figure 1. A parts list is given in Table 1. The computer controlled valve (S) is used to select the gas inflow from different gas sources at approximately atmospheric pressure. The capillary (C) controls the gas flow from the gas inlet into the vacuum system. The continuous gas flow from the capillary into the quadrupole mass spectrometer (QMS) is balanced by the turbomolecular pump (TP), which produces a high vacuum in the QMS. The gas species in the QMS are ionised in the open, cylindrically symmetrical ion source by electron impact ionisation (in this work, the ionisation energy was always set to $70 \mathrm{eV}$ unless noted otherwise). The resulting ion beam then passes a quadrupole mass filter set to a specific $m / z$ ratio ( $m$ : ion mass number, $z$ : ion charge number), and the ion beam strength at this $m / z$ value is quantified using either a Faraday cup $(\mathrm{F})$ or a secondary electron multiplier (M) detector.

\section{Gas inlet system}

The sample gas pressure is reduced from approximately atmospheric pressure to the high vacuum in the QMS using a $10 \mathrm{~m}$ long capillary with an inner diameter of $0.1 \mathrm{~mm}$. The rugged 1/16" stainless-steel capillary tubing prevents the leakage of $\mathrm{He}$ and other mobile gases through the tubing walls. We empirically determined the gas flow though this capillary to $0.06 \mathrm{~cm}_{\mathrm{STP}}^{3} / \mathrm{min}$. This gas flow results in a total gas pressure of approximately $2 \times 10^{-8}$ bar in the MS vacuum chamber, which yields maximum overall sensitivity of the MS while not exceeding the linear operation range of the MS. The observed travel time of the gas from the capillary inlet to the QMS is approximately $80 \mathrm{~s}$. An instantaneous step-like concentration change at the capillary inlet is smeared out over approximately 10 s (50\% rise time) once it reaches the QMS, resulting in an analytical time resolution of $\lesssim 1 \mathrm{~min}$.

Compared to MS systems with a typical two-stage pressure reduction using a capillary followed by a pinhole/bypass system, the miniRuedi gas consumption is lower by several orders of 
magnitudes. The system is therefore most suitable for applications where low gas consumption is beneficial, such as the GE-MIMS technique. With a typical total gas concentration in air-saturated water of approximately $25 \mathrm{~cm}_{\mathrm{STP}}^{3} / \mathrm{L}$, a water flow rate of $\gtrsim 0.1 \mathrm{~L} / \mathrm{min}$ through the membrane contactor would provide more than $100 \times$ the gas amount consumed by the miniRuedi. This illustrates how the miniRuedi allows unbiased GE-MIMS analysis at low water flow rates. Furthermore, pinhole/bypass stages or similar flow bifurcations may introduce uncontrollable fractionation of gas species in vacuum systems. Such artefacts are avoided in the miniRuedi by the absence of such a secondary pressure reduction stage.

\section{Data processing and calibration}

The peak heights in the $m / z$ spectrum are recorded in a user-defined sequence of the relevant $m / z$ values using the $\mathrm{F}$ and $\mathrm{M}$ detectors, and repeated readings are averaged over a time interval suitable for a given application. The means $\left(s_{m / z}\right)$ of the peak heights recorded during each interval at each $m / z$ ratio are used as the raw measurement results of each measurement step. The $s_{m / z}$ values obtained from sample or standard-gas analyses are corrected for the instrument blank by subtracting the $s_{m / z}$ values obtained with the inlet valve V closed.

The blank-corrected $s_{m / z}$ values are calibrated in terms of the partial pressures of the different gas species in the sampled gas by peak height comparison relative to a reference gas with well known partial pressures of the species of interest. The mixing ratios of the different gas species in the gas are unaffected by the gas passage through the capillary, because the viscous flow regime prevailing throughout most of the capillary prevents fractionation of the gas species. For a given total gas pressure at the capillary inlet, the peak height at a given $m / z$ value is therefore linearly related to the partial pressure of the respective gas species in the sampled gas. Note, however, that the capillary gas flow approaches the molecular flow regime at the outlet to the QMS vacuum. The rate of the total gas flow through capillary is therefore not a perfectly linear function of the total gas pressure at the capillary inlet. ${ }^{54}$ We found this nonlinearity to be negligible for the quantification of the partial pressures (bias $<1 \%$ ) if the pressure difference between the sample gas and the 
reference gas at the capillary inlet is $\lesssim 50$ mbar. For larger pressure differences, accurate partial pressures are obtained by normalising their sum to correspond to the true sample gas pressure at the capillary inlet.

In many environmental applications, ambient air can be used as a well-defined and convenient gas standard for noble gases, $\mathrm{N}_{2}$ and $\mathrm{O}_{2}$. A dedicated standard-gas mixture is only required for species with unknown or variable atmospheric partial pressures, or if the sampled partial pressures are vastly different from those in air, for example in systems with high abundances of $\mathrm{CO}_{2}, \mathrm{CH}_{4}$ or (non-atmospheric) He.

In order to account for drifts in the instrument sensitivity resulting from changes in the flow resistance of the gas inlet or the sensitivity of the mass spectrometer, the standard gas is analysed periodically in between sample gas analyses. The $s_{m / z}$ values obtained in a given sample-gas analysis step are then calibrated using the $s_{m / z}$ values of the standard-gas analysis steps interpolated to the analysis time of the sample gas step. Finally, the standard error of the sample gas analyses is estimated from the standard deviation of replicate analysis results obtained from standard gases.

\section{Results and Discussion}

\section{Laboratory tests}

To test the linearity of the $s_{m / z}$ values in response to variations in the partial pressures of the gas species at the capillary inlet, we prepared a gas mixture with mixing ratios of approximately $7.0 \% \mathrm{He}, 0.24 \% \mathrm{CH}_{4}, 16 \% \mathrm{O}_{2}, 72 \% \mathrm{~N}_{2}, 1.8 \% \mathrm{Ar}$, and $3.1 \% \mathrm{CO}_{2}$. This test gas was kept in a gas sampling bag (Linde, Plastigas) and was incrementally diluted with $99.999 \%$ pure $\mathrm{N}_{2}$. The dilution factor was determined by quantifying the $\mathrm{CO}_{2}$ and $\mathrm{CH}_{4}$ mixing ratios of the dilution using a cavity ring-down spectroscopy analyser (Picarro G2201-i). Figure 2 shows the peak heights obtained from analyses of each test gas dilution step, whereby the total pressure of the gas mixture and its dilutions in the sample bag was always kept at ambient pressure $(960 \mathrm{hPa})$. This dilution test confirms that the $\mathrm{F}$ and $\mathrm{M}$ peak heights at a given $\mathrm{m} / \mathrm{z}$ value are linear functions of the partial 
pressure of the respective gas species at the capillary inlet.

To assess the drift of the $\mathrm{F}$ and $\mathrm{M}$ sensitivity over time, the instrument was set to continuously analyse an air sample during $70 \mathrm{~h}$ in a laboratory with stable ambient temperature. Figure 3 shows the Allan deviations ${ }^{55}$ of the resulting $\mathrm{F}$ and $\mathrm{M}$ signals. The Allan deviations reflect the errors of the means of the $\mathrm{F}$ and $\mathrm{M}$ signals as a function of the averaging time. Both the $\mathrm{F}$ and $\mathrm{M}$ Allan deviations exhibit a minimum at an averaging time of approximately $1 \mathrm{~h}$. For shorter averaging times, the uncertainties of the $\mathrm{F}$ and $\mathrm{M}$ signal means are dominated by random noise, whereas for longer averaging times the uncertainties of the means are dominated by instrument drift. To minimise the effects of drift on the measurement results, peak-height readings should therefore not be averaged for longer than $1 \mathrm{~h}$, and drift calibrations should be run at least hourly. However, changes in ambient temperature will affect the sensitivity of the instrument, mainly because the flow resistance of the capillary decreases with increasing temperature. Averaging time and drift calibration intervals therefore need to be adapted to changes in the ambient conditions. In addition, the choice of the averaging time and the drift calibration intervals will also need to be adapted to the time resolution of the measurement results required to assess the gas dynamics of the system being studied.

The Allan deviation corresponds to the resolving power of the measurement and hence indicates the analytical precisions and the limits of detection ${ }^{55}$ that can be achieved with the $\mathrm{F}$ and $\mathrm{M}$ detectors at any given $m / z$ value. The minima of the relative Allan deviations for $\mathrm{He}(\mathrm{M}, m / z=4)$, $\mathrm{Ne}(\mathrm{M}, m / z=20), \mathrm{N}_{2}(\mathrm{~F}, m / z=28), \mathrm{O}_{2}(\mathrm{~F}, m / z=32), \operatorname{Ar}(\mathrm{M}, m / z=36 ; \mathrm{F}, m / z=40)$, and $\mathrm{Kr}(\mathrm{M}, m / z=84)$ all correspond to $0.3-0.6 \%$ of the respective partial pressure in the atmosphere. The typical limits of detection are therefore estimated to approximately $1 \%$ of the partial pressure of the respective gases in the atmosphere.

The absence of any gas purification stage requires special attention to avoid matrix effects related to ions of different gas species that contribute to the same signal at a given $m / z$ ratio, e.g., due to multiple ionisation of gas species or isobaric gas molecules ${ }^{56}$ Multiple ionisation can be reduced substantially by reducing the electron impact energy in the ioniser unit in the QMS. ${ }^{57}$ 
In particular, the interferences occurring at $m / z=16\left({ }^{12} \mathrm{CH}_{4}^{+}\right.$and ${ }^{16} \mathrm{O}_{2}^{2+}$ ions $)$ and at $m / z=20$ $\left({ }^{20} \mathrm{Ne}^{+}\right.$and ${ }^{40} \mathrm{Ar}^{2+}$ ions) may be of special relevance for the targeted applications of the miniRuedi. Figure 4-A shows the F peak heights obtained from analysis of pure $\mathrm{Ar}$ at $m / z=40\left({ }^{40} \mathrm{Ar}^{+}\right)$and $m / z=20\left({ }^{40} \mathrm{Ar}^{2+}\right)$ as a function of the electron energy. For electron energies below $50 \mathrm{eV}$, the ${ }^{40} \mathrm{Ar}^{2+} /{ }^{40} \mathrm{Ar}^{+}$ratio is less than $3 \cdot 10^{-5}$, which is approximately two orders of magnitude lower than the ${ }^{20} \mathrm{Ne} /{ }^{40} \mathrm{Ar}$ ratio in air $\left(1.77 \cdot 10^{-3}\right)$. Using electron energies of $50 \mathrm{eV}$ or less will therefore reduce the ${ }^{40} \mathrm{Ar}^{2+}$ interference to a level where it can easily be compensated or even neglected for ${ }^{20} \mathrm{Ne}$ analysis in air-like gases (Figure 4-B). However, we observed that ${ }^{20}\left(\mathrm{H}_{2} \mathrm{O}\right)$ molecules may contribute up to $\sim 50 \%$ to the $m / z=20$ signal in moist air-like gas matrices (such as in GE-MIMS analyses). ${ }^{20} \mathrm{Ne}$ quantification is therefore recommended in dry gases only and requires careful compensation of the residual ${ }^{20}\left(\mathrm{H}_{2} \mathrm{O}\right)$ contribution, which may be estimated from the the $m / z=18$ signal and by assuming a typical ${ }^{20}\left(\mathrm{H}_{2} \mathrm{O}\right) /{ }^{18}\left(\mathrm{H}_{2} \mathrm{O}\right)$ ratio. Apart from these interferences, we did not observe any significant interferences that would affect the gas analysis on the $m / z$ values shown in Figure 2. Nevertheless, it is important to note that such interferences may become relevant in gas matrices that are very different from the air-like gas assessed in this work.

To test the miniRuedi performance as a GE-MIMS with miniature membrane contactors at low water flow, we compared GE-MIMS measurements using miniature membrane contactors (LiquiCel G591, $11 \mathrm{~cm}^{3}$ external volume) with measurements using the large membrane contactor as used with our original GE-MIMS ${ }^{49}$ (Liqui-Cel G542, $260 \mathrm{~cm}^{3}$ external volume). The miniature contactors were operated either as a single unit or as a parallel combination of two units. Groundwater was pumped through the membrane contactors, and tee branches were used to split the water flow among the membrane contactors for parallel operation of the miniature and the large contactors. The flow rates were $0.4 \mathrm{~L} / \mathrm{min}$ through each miniature contactor and $2 \mathrm{~L} / \mathrm{min}$ through the large contactor. 10 measurements were made with each miniature contactor setup (single or two parallel contactors). Each miniature-contactor measurement was bracketed with a measurement using the large contactor. Figure 5 shows that using a single miniature contactor may result in a small bias of the gas partial pressures relative to those observed in the large contactor. For the tested gas 
species shown in Figure 5, the bias is largest for $\mathrm{CO}_{2}$ (approximately 8\%), but much smaller for the remaining gases $\left(\mathrm{He}, \mathrm{Ar}, \mathrm{Kr}, \mathrm{N}_{2}\right)$. However, using two miniature contactors removes the bias for all gases. The low gas consumption of the miniRuedi therefore obviates the compensation for gas depletion in the membrane contactor and allows absolute GE-MIMS measurements with much smaller membrane contactors and water flows than the previous GE-MIMS instrument ${ }^{49}$, which requires a water flow of $\geq 2 \mathrm{~L} / \mathrm{min}$.

\section{Field test (accuracy and precision)}

To quantify the accuracy and precision of the miniRuedi with the GE-MIMS method, we carried out a series of 42 GE-MIMS measurements (using a Liqui-Cel G542 contactor) of the ${ }^{4} \mathrm{He}, \mathrm{N}_{2},{ }^{40} \mathrm{Ar}$ and ${ }^{84} \mathrm{Kr}$ concentrations in a small creek (Chriesbach, Switzerland). The concentrations of these inert atmospheric gases in the creek are in equilibrium with their atmospheric partial pressure and therefore serve as a well defined reference for comparison with the measured concentrations. In addition, 29 air replicates were analysed to determine the precision of the miniRuedi measurements without the GE-MIMS contactor. Air standards for drift calibration were carried out in between the sample analyses. For each measurement, the peak heights at $m z=4,28,40$ and 84 were integrated for $10 \mathrm{~min}$.

The residuals $r_{i}=\left(C_{\mathrm{m}, i}-C_{\mathrm{e}, i}\right) / C_{\mathrm{e}, i}$ of the measured concentrations in the water $\left(C_{\mathrm{m}, i}, i=\right.$ $1 \ldots 42)$ relative to the atmospheric equilibrium concentrations $\left(C_{\mathrm{e}, i}\right)$ were computed from the solubility of the respective gas at the water temperature that prevailed at the time of the corresponding measurement $\left(13.4^{\circ} \mathrm{C}\right.$ to $\left.15.7^{\circ} \mathrm{C}\right)$. The means of the $r_{i}(\mu$ in Table 2) indicate that the accuracy of the miniRuedi analysis with the GE-MIMS method was $0.9 \%$ or better for all gases. The standard deviations of the $r_{i}(\sigma)$ indicate that the overall precision of the miniRuedi analysis with the GE-MIMS method ranged from $1.2 \%$ to $3.3 \%$. The standard deviations of the air replicates analysed without the GE-MIMS contactor $\left(\sigma_{\text {air }}\right)$ are only marginally smaller. The loss of precision associated with the addition the GE-MIMS contactor to the miniRuedi is therefore small. 


\section{Application examples}

In the three application examples below, we demonstrate the utility of the miniRuedi for the analysis of the gas dynamics in different environmental systems and field settings. The examples were chosen to cover both gaseous and aqueous matrices and to span a wide range of processes and rates controlling the natural gas dynamics.

\section{Soil gas formation}

Figure 6 shows the concentrations of $\mathrm{Ar}, \mathrm{N}_{2}, \mathrm{O}_{2}, \mathrm{CO}_{2}$, and $\mathrm{CH}_{4}$ determined with the miniRuedi in the soil gas of a bioreactor landfill located in north-eastern Switzerland. The landfill is being prepared for active aerobisation by technical means in order to foster aerobic decomposition of the mostly organic wastes to $\mathrm{CO}_{2}$ in favour of anaerobic decomposition to the more potent greenhouse gas $\mathrm{CH}_{4}$. To this end, the landfill has been sealed at the top. The ongoing production of landfill gases therefore results in a steady gas outflow from the 5 observation wells, where the gases were sampled in gas-tight $500 \mathrm{~mL}$ stainless-steel flasks. We connected the flasks to the miniRuedi gas inlet to determine the concentrations of the various gas species in these samples. The concentrations of $\mathrm{Ar}, \mathrm{N}_{2}$, and $\mathrm{O}_{2}$ were calibrated using ambient air, whereas gas mixtures of $10 \% \mathrm{CO}_{2}$ in $\mathrm{N}_{2}$ and $10 \% \mathrm{CH}_{4}$ in $\mathrm{N}_{2}$ were used for $\mathrm{CO}_{2}$ and $\mathrm{CH}_{4}$ calibration. As expected, the observed $\mathrm{O}_{2}$ concentrations are low in all 5 observation wells (0.5-2\%). The concentrations of the remaining gases indicate a binary mixture of landfill gas $\left(\mathrm{CO}_{2}, \mathrm{CH}_{4}\right)$ and oxygen-depleted air $\left(\mathrm{N}_{2}\right.$, Ar). The Ar concentration yields a direct quantification of the relative proportions of these two endmembers and hence allows quantification of the air-derived $\mathrm{O}_{2}$ that has been transformed within the landfill. In addition, the $\mathrm{N}_{2} / \mathrm{Ar}$ ratio is elevated in one well by approximately $30 \%$ relative to the atmospheric ratio, which points to $\mathrm{N}_{2}$ production by denitrification. Such combined analyses of inert and active gas species are therefore highly beneficial to quantify the turnover of $\mathrm{O}_{2}$ and other gases and thus allows assessing the efficiency of landfill aerobisation. 


\section{Lake/atmosphere gas exchange}

Figure 7 shows the partial pressures of $\mathrm{Ar}, \mathrm{N}_{2}, \mathrm{O}_{2}, \mathrm{CO}_{2}$, and $\mathrm{CH}_{4}$ in a floating chamber deployed on the water surface of Lake Soppensee (central Switzerland). Such floating chambers are used to isolate a section of the water surface $\left(0.126 \mathrm{~m}^{2}\right)$ from the atmosphere in order to study $\mathrm{CO}_{2}$ and $\mathrm{CH}_{4}$ fluxes across the water surface using a $\mathrm{CO}_{2} / \mathrm{CH}_{4}$ analyser. ${ }^{58}$ The mass balance of the gas species in the chamber is controlled by the gas exchange across the isolated section of the water surface. We connected the gas inlet of the miniRuedi to the floating chamber and recorded the change in the partial pressures in the headspace after deployment on the lake during $12 \mathrm{~min}$. The volume of the gas transferred into the miniRuedi gas inlet during this period corresponds to less than $0.05 \%$ of the floating chamber volume $(19.1 \mathrm{~L})$. The effect of the gas consumption of the miniRuedi on the mass balance of the gas species in the floating chamber is therefore negligible. After deployment of the floating chamber, the $\mathrm{CH}_{4}$ and $\mathrm{CO}_{2}$ partial pressures showed a marked increase relative to the atmospheric background, because the surface water of the hypertrophic lake was strongly supersaturated with these gases. In contrast, the surface water was undersaturated in $\mathrm{O}_{2}$ relative to the atmospheric equilibrium (30\% saturation) due to aerobic respiration and possibly also $\mathrm{CH}_{4}$ oxidation, rapid cooling of the surface water, and mixing with $\mathrm{O}_{2}$-depleted deep water. Despite the large atmospheric $\mathrm{O}_{2}$ background of the initial air trapped in the floating chamber, the decrease of the $\mathrm{O}_{2}$ partial pressure due to $\mathrm{O}_{2}$ transfer to the water is small, but quantifiable. In contrast, the Ar and $\mathrm{N}_{2}$ concentrations in the water were closer to saturation (both at $75 \%$ saturation), and no systematic changes in the Ar and $\mathrm{N}_{2}$ partial pressures in the float chamber are observed. The miniRuedi thus allows expanding the float chamber method for quantification of $\mathrm{CO}_{2}$ and $\mathrm{CH}_{4}$ fluxes to $\mathrm{Ar}, \mathrm{N}_{2}, \mathrm{O}_{2}$, and possibly also other gas species. In particular, the gas consumed for miniRuedi analysis does not interfere with the mass balance of the gas species in the floating chamber. The miniRuedi might thus provide new insights into the rates and physical processes controlling gas/water exchange, such as enhanced air/water exchange mediated by microbubbles present in the water body. ${ }^{58}$ 


\section{Seafloor gas emanation}

Figure 8 shows the concentrations of $\mathrm{He}, \mathrm{CO}_{2}$, and $\mathrm{CH}_{4}$ observed in deep-water samples taken in the Gulf of California (Mexico). These gases are associated with hydrothermal fluids released from black smokers or other fluid vents at the seafloor. ${ }^{59}$ At each sampling location, replicate deepwater samples were collected in $10 \mathrm{~L}$ Niskin samplers. Immediately after retrieval of the Niskin samplers, one replicate was screened for the dissolved-gas concentrations with the miniRuedi using the GE-MIMS method. To allow GE-MIMS analysis with such a limited amount of water, two parallel miniature membrane contactors (Liqui-Cel G591) were used with a total water flow of $0.5 \mathrm{~L} / \mathrm{min}$ from the Niskin samplers. The small gas volume of the miniature membrane contactors facilitates fast gas/water equilibration within approximately $3 \mathrm{~min}$ after starting the water flow. Therefore, more than $15 \mathrm{~min}$ were left for GE-MIMS analysis of the water flowing from the Niskin samplers. The dissolved-gas concentrations obtained from the GE-MIMS screening were used to optimise the the selection of subsamples from the remaining Niskin samplers for after-cruise laboratory-based analyses of ${ }^{3} \mathrm{He} /{ }^{4} \mathrm{He}$ and $\delta^{13} \mathrm{C}$ of the fluids emitted from the black smokers. ${ }^{59}$ The new possibility for rapid on-board GE-MIMS screening of relatively small sample volumes $(10 \mathrm{~L})$ proved to be highly beneficial for identifying target samples for post-cruise analyses in specialised labs. In addition, data turnaround time was reduced and the quality of the ${ }^{3} \mathrm{He} /{ }^{4} \mathrm{He}$ and $\delta^{13} \mathrm{C}$ data set used for detailed characterisation of the hydrothermal fluids was optimised.

\section{Assessment}

Our laboratory tests and field applications demonstrate the performance and flexibility of the miniRuedi for on-site gas analysis in a wide range of environmental systems and applications. The miniRuedi provides real-time partial pressure measurements of $\mathrm{He}, \mathrm{Ne}$ (in dry gas), $\mathrm{Ar}, \mathrm{Kr}$, $\mathrm{N}_{2}, \mathrm{O}_{2}, \mathrm{CO}_{2}$ and $\mathrm{CH}_{4}$ both in gaseous and aqueous matrices. The low gas consumption opens up new possibilities for unbiased GE-MIMS quantification of dissolved gas concentrations at low water flow, gas analysis in flux chambers, and other systems with low gas throughput where sample gas consumption must be minimised to avoid interference with the natural gas dynamics. In con- 
trast to earlier systems aimed at environmental gas analysis, the miniRuedi is highly suitable for on-site gas analysis in various environmental systems and at remote locations due to its portability, low power requirements, and maintenance-free operation. The on-site data availability and the high temporal resolution of time-series data are crucial benefits over conventional methods based on expensive and often laborious laboratory analyses of single samples. The miniRuedi therefore opens new opportunities for the combined analysis of inert ( $\left.\mathrm{He}, \mathrm{Ne}, \mathrm{Ar}, \mathrm{Kr}, \mathrm{N}_{2}\right)$ and reactive gases $\left(\mathrm{O}_{2}, \mathrm{CO}_{2}, \mathrm{CH}_{4}\right.$, etc. $)$, which provides the basis for quantitative studies of environmental processes and their interplay in terms of physical, chemical, and biological mechanisms.

\section{Acknowledgement}

We thank Philipp Weber for support with the lab tests and Anja Bretzler for editing assistance. Further, we thank the four anonymous reviewers for their constructive comments. 


\section{References}

(1) Cook, P., Herczeg, A., Eds. Environmental Tracers in Subsurface Hydrology; Kluwer Academic Publishers: Boston, Dordrecht, London, 2000.

(2) Kipfer, R.; Aeschbach-Hertig, W.; Peeters, F.; Stute, M. In Noble gases in geochemistry and cosmochemistry; Porcelli, D., Ballentine, C., Wieler, R., Eds.; Rev. Mineral. Geochem.; Mineralogical Society of America, Geochemical Society, 2002; Vol. 47; pp 615-700.

(3) Aeschbach-Hertig, W.; Solomon, D. In The Noble Gases as Geochemical Tracers; Burnard, P., Ed.; Advances in Isotope Geochemistry; Springer: Heidelberg, New York, Dordrecht, London, 2013; pp 81-122.

(4) Brennwald, M. S.; Vogel, N.; Scheidegger, Y.; Tomonaga, Y.; Livingstone, D. M.; Kipfer, R. In The Noble Gases as Geochemical Tracers; Burnard, P. G., Ed.; Advances in Isotope Geochemistry; Springer, 2013; pp 123-153.

(5) Stanley, R. H. R.; Jenkins, W. J. In The Noble Gases as Geochemical Tracers; Burnard, P., Ed.; Advances in Isotope Geochemistry; Springer, 2013; pp 55-79.

(6) Aeschbach-Hertig, W.; Peeters, F.; Beyerle, U.; Kipfer, R. Interpretation of dissolved atmospheric noble gases in natural waters. Water Resour. Res. 1999, 35, 2779-2792.

(7) Beyerle, U.; Aeschbach-Hertig, W.; Hofer, M.; Imboden, D. M.; Baur, H.; Kipfer, R. Infiltration of river water to a shallow aquifer investigated with ${ }^{3} \mathrm{H} /{ }^{3} \mathrm{He}$, noble gases and CFCs. $J$. Hydrol. 1999, 220, 169-185.

(8) Aeschbach-Hertig, W.; Peeters, F.; Beyerle, U.; Kipfer, R. Palaeotemperature reconstruction from noble gases in ground water taking into account equilibration with entrapped air. Nature 2000, 405, 1040-1044.

(9) Hohmann, R.; Schlosser, P.; Jacobs, S.; Ludin, A.; Weppernig, R. Excess helium and neon in the southeast Pacific: Tracers for glacial meltwater. J. Geophys. Res.-Oceans 2002, 107, 3198.

(10) Thomas, J. M.; Hudson, G. B.; Stute, M.; Clark, J. F. Noble gas loss may indicate groundwater flow across flow barriers in southern Nevada. Env. Geol. 2003, 43, 568-579.

(11) Brennwald, M. S.; Imboden, D. M.; Kipfer, R. Release of gas bubbles from lake sediment traced by noble gas isotopes in the sediment pore water. Earth Planet. Sci. Lett. 2005, 235 , $31-44$.

(12) Huber, C.; Beyerle, U.; Leuenberger, M.; Schwander, J.; Kipfer, R.; Spahni, R.; Severinghaus, J. P.; Weiler, K. Evidence for molecular size dependent gas fractionation in firn air derived from noble gases, oxygen, and nitrogen measurements. Earth Planet. Sci. Lett. 2006, $243,61-73$.

(13) Severinghaus, J. P.; Battle, M. Fractionation of gases in polar ice during bubble close-off: new constraints from firn air Ne, Kr, and Xe observations. Earth Planet. Sci. Lett. 2006, 244 , 474-500. 
(14) Klump, S.; Kipfer, R.; Cirpka, O. A.; Harvey, C. F.; Brennwald, M. S.; Ashfaque, K. N.; Badruzzaman, A. B. M.; Hug, S. J.; Imboden, D. M. Groundwater Dynamics and Arsenic Mobilization in Bangladesh Assessed using Noble Gases and Tritium. Environ. Sci. Technol. 2006, 40, 243-250.

(15) Klump, S.; Tomonaga, Y.; Kienzler, P.; Kinzelbach, W.; Baumann, T.; Imboden, D.; Kipfer, R. Field experiments yield new insights into gas exchange and excess air formation in natural porous media. Geochim. Cosmochim. Acta 2007, 71, 1385-1397.

(16) Cey, B. D.; Hudson, G. B.; Moran, J. E.; Scanlon, B. R. Impact of Artificial Recharge on Dissolved Noble Gases in Groundwater in California. Environ. Sci. Technol. 2008, 42, 10171023, PMID: 18351066.

(17) Klump, S.; Cirpka, O.; Surbeck, H.; Kipfer, R. Experimental and numerical studies on excessair formation in quasi-saturated porous media. Water Resour. Res. 2008, 44, W05402.

(18) Holzner, C. P.; McGinnis, D. F.; Schubert, C. J.; Kipfer, R.; Imboden, D. M. Noble gas anomalies related to high-intensity methane gas seeps in the Black Sea. Earth Planet. Sci. Lett. 2008, 265, 396-409.

(19) Althaus, R.; Klump, S.; Onnis, A.; Kipfer, R.; Purtschert, R.; Stauffer, F.; Kinzelbach, W. Noble gas tracers for characterisation of flow dynamics and origin of groundwater: A case study in Switzerland. J. Hydrol. 2009, 370, 64-72.

(20) Chaduteau, C.; Jean-Baptiste, P.; Fourré, E.; Charlou, J.-L.; Donval, J.-P. Helium transport in sediment pore fluids of the Congo-Angola margin. Geochem. Geophys. Geosyst. 2009, 10, Q01002.

(21) Pitre, F.; Pinti, D. L. Noble gas enrichments in porewater of estuarine sediments and their effect on the estimation of net denitrification rates. Geochim. Cosmochim. Acta 2010, 74, 531-539.

(22) Severinghaus, J. P.; Albert, M. R.; Courville, Z. R.; Fahnestock, M. A.; Kawamura, K.; Montzka, S. A.; Mühle, J.; Scambos, T. A.; Shields, E.; Shuman, C. A.; Suwa, M.; Tans, P.; Weiss, R. F. Deep air convection in the firn at a zero-accumulation site, central Antarctica. Earth Planet. Sci. Lett. 2010, 293, 359-367.

(23) Hall, C. M.; Castro, M. C.; Lohmann, K. C.; Sun, T. Testing the noble gas paleothermometer with a yearlong study of groundwater noble gases in an instrumented monitoring well. Water Resour. Res. 2012, 48, W04517.

(24) Grundl, T.; Magnusson, N.; Brennwald, M. S.; Kipfer, R. Mechanisms of subglacial groundwater recharge as derived from noble gas, ${ }^{14} \mathrm{C}$, and stable isotopic data. Earth Planet. Sci. Lett. 2013, 369-370, 78-85.

(25) Loose, B.; Jenkins, W. J. The five stable noble gases are sensitive unambiguous tracers of glacial meltwater. Geophys. Res. Lett. 2014, 41, 2835-2841. 
(26) Tomonaga, Y.; Brennwald, M. S.; Meydan, A. F.; Kipfer, R. Noble gases in the sediments of Lake Van - Solute transport and palaeoenvironmental reconstruction. Quaternary Sci. Rev. 2014, 104, 117-126.

(27) Tomonaga, Y.; Brennwald, M. S.; Kipfer, R. Attenuation of diffusive noble-gas transport in laminated sediments of the Stockholm Archipelago. Limnol. Oceanogr. 2015, 60, 497-511.

(28) Tomonaga, Y.; Brennwald, M. S.; Livingstone, D. M.; Tomonaga, G.; Kipfer, R. Determination of Natural In Vivo Noble-Gas Concentrations in Human Blood. PLOS ONE 2014, 9 , e96972.

(29) Thevis, M.; Piper, T.; Geyer, H.; Thomas, A.; Schaefer, M. S.; Kienbaum, P.; Schänzer, W. Measuring xenon in human plasma and blood by gas chromatography/mass spectrometry. Rapid Comm. Mass Spectrometry 2014, 28, 1501-1506.

(30) Stanley, R. H. R.; Kirkpatrick, J. B.; Cassar, N.; Barnett, B. A.; Bender, M. L. Net community production and gross primary production rates in the western equatorial Pacific. Global Biogeochem. Cycles 2010, 24, GB4001.

(31) Freundt, F.; Schneider, T.; Aeschbach-Hertig, W. Response of noble gas partial pressures in soil air to oxygen depletion. Chem. Geol. 2013, 339, 283-290.

(32) Mächler, L.; Brennwald, M. S.; Kipfer, R. Argon Concentration Time-Series As a Tool to Study Gas Dynamics in the Hyporheic Zone. Environ. Sci. Technol. 2013, 47, 7060-7066.

(33) Mächler, L.; Peter, S.; Brennwald, M. S.; Kipfer, R. Excess air formation as a mechanism for delivering oxygen to groundwater. Water Resour. Res. 2013, 49, 1-10.

(34) Eveleth, R.; Timmermans, M.-L.; Cassar, N. Physical and biological controls on oxygen saturation variability in the upper Arctic Ocean. J. Geophys. Res.-Oceans 2014, 119, 74207432.

(35) Peter, S.; Mächler, L.; Kipfer, R.; Wehrli, B.; Durisch-Kaiser, E. Flood-Controlled ExcessAir Formation Favors Aearobic Respiraton and Limits Denitrification Activity in Riparian Groundwater. Frontiers Env. Sci. 2015, 3.

(36) Hofer, M.; Imboden, D. M. Simultaneous determination of CFC-11, CFC-12, $\mathrm{N}_{2}$ and Ar in water. Anal. Chem. 1998, 70, 724-729.

(37) Beyerle, U.; Aeschbach-Hertig, W.; Imboden, D. M.; Baur, H.; Graf, T.; Kipfer, R. A mass spectrometric system for the analysis of noble gases and tritium from water samples. Environ. Sci. Technol. 2000, 34, 2042-2050.

(38) Kulongoski, J. T.; Hilton, D. R. A quadrupole-based mass spectrometric system for the determination of noble gas abundances in fluids. Geochem. Geophys. Geosyst. 2002, 3, 1-10.

(39) Stanley, R. H. R.; Baschek, B.; Lott III, D. E.; Jenkins, W. J. A new automated method for measuring noble gases and their isotopic ratios in water samples. Geochem. Geophys. Geosyst. 2009, 10, Q05008. 
(40) Sültenfuss, J.; Roether, W.; Rhein, M. The Bremen mass spectrometric facility for the measurement of helium isotopes, neon, and tritium in water. Isotopes In Environmental and Health Studies 2009, 45, 83-95.

(41) Brennwald, M. S.; Hofer, M.; Kipfer, R. Simultaneous analysis of noble gases, sulphur hexafluoride and other dissolved gases in water. Environ. Sci. Technol. 2013, 47, 8599-8608.

(42) Visser, A.; Singleton, M. J.; Hillegonds, D. J.; Velsko, C. A.; Moran, J. E.; Esser, B. K. A membrane inlet mass spectrometry system for noble gases at natural abundances in gas and water samples. Rapid Communications in Mass Spectrometry 2013, 27, 2472-2482.

(43) Kotiaho, T. On-site Environmental and In Situ Process Analysis by Mass Spectrometry. Journal of Mass Spectrometry 1996, 31, 1-15.

(44) Ketola, R. A. In Environmental Instrumentation and Analysis Handbook; Randy D. Down P E, R. D., Lehr, J. H., Eds.; Wiley, 2005; pp 187-220.

(45) Schlüter, M.; Gentz, T. Application of Membrane Inlet Mass Spectrometry for Online and In Situ Analysis of Methane in Aquatic Environments. J. Am. Soc. Mass Spectromet. 2008, 19, 1395-1402.

(46) Gentz, T.; Schlüter, M. Underwater cryotrap-membrane inlet system (CT-MIS) for improved in situ analysis of gases. Limnol. Oceanogr. Methods 2012, 10, 317-238.

(47) Sommer, S.; Schmidt, M.; Linke, P. Continuous inline tracking of dissolved methane plume at a blowout site in the Northern North Sea UK - water column stratification impedes immediate methane release into the atmosphere. Marine and Petroleum Geology 2015, 68, 766-775.

(48) Schmidt, M.; Linke, P.; Sommer, S.; Esser, D.; Cherednichenko, S. Natural $\mathrm{CO}_{2}$ seeps offshore Panarea - A test site for subsea $\mathrm{CO}_{2}$ leak detection technology. Marine Technology Society Journal 2015, 49, 19-30.

(49) Mächler, L.; Brennwald, M. S.; Kipfer, R. Membrane Inlet Mass Spectrometer for the QuasiContinuous On-Site Analysis of Dissolved Gases in Groundwater. Environ. Sci. Technol. 2012, 46, 8288-8296.

(50) Cassar, N.; Barnett, B.; Bender, M. L.; Kaiser, J.; Hamme, R. C.; Tilbrook, B. Continuous High-Frequency Dissolved $\mathrm{O}_{2} /$ Ar Measurements by Equilibrator Inlet Mass Spectrometry. Anal. Chem. 2009, 81, 1855-1864.

(51) Manning, C. C.; Stanley, R. H. R.; Lott III, D. E. Continuous Measurements of Dissolved Ne, $\mathrm{Ar}, \mathrm{Kr}$, and Xe Ratios with a Field-Deployable Gas Equilibration Mass Spectrometer. Anal. Chem. 2016, 88, 3040-3048.

(52) Mächler, L. Quantification of oxygen turnover in groundwater by continuous on-site gas concentration measurements. Ph.D. thesis, ETH Zürich, 2012.

(53) Mächler, L.; Brennwald, M. S.; Tyroller, L.; Livingstone, D. M.; Kipfer, R. Conquering the Outdoors with On-Site Mass Spectrometry. Chimia 2014, 68, 155-159. 
(54) Fryer, G. M. A theory of gas flow through capillary tubes. Proc. Royal Soc. London, Ser. A Math. Phys. Sci. 1966, 293, 329-341.

(55) Werle, P.; Mücke, R.; Slemr, F. The Limits of Signal Averaging in Atmospheric Trace-Gas Monitoring by Tunable Diode-Laser Absorption Spectroscopy (TDLAS). Appl. Phys. B 1993, 131-139.

(56) Burnard, P.; Zimmermann, L.; Sano, Y. In The Noble Gases as Geochemical Tracers; Burnard, P., Ed.; Advances in Isotope Geochemistry; Springer, 2013; pp 1-15.

(57) Davies, S.; Rees, J. A.; Seymour, D. L. Threshold ionisation mass spectrometry (TIMS); a complementary quantitative technique to conventional mass resolved mass spectrometry. Vacuum 2014, 101, 416-422.

(58) McGinnis, D. F.; Kirillin, G.; W, T. K.; Flury, S.; Bodmer, P.; Engelhardt, C.; Casper, P.; Grossart, H.-P. Enhancing Surface Methane Fluxes from an Oligotrophic Lake: Exploring the Microbubble Hypothesis. Environ. Sci. Technol. 2015, 49, 873-880.

(59) Berndt, C. et al. Rifting under steam - how rift magmatism triggers methane venting from sedimentary basins. Geology 2016, G38049.1. 


\section{Tables}

Table 1: Parts list (see also Figure 1).

\begin{tabular}{cl}
\hline Part & Description \\
\hline S & 6-port inlet selector valve (VICI C5-2306EMHY) \\
C & 10m stainless steel tubing with 0.1 mm inner diameter (VICI TSS104) \\
V & Inlet valve (Swagelok SS-4H) \\
QMS & Quadrupole mass spectrometer with Faraday cup and secondary electron mul- \\
& tiplier detectors (Stanford Research Systems RGA-200) \\
TP & Turbomolecular pump with 70 L/s pumping speed (Pfeiffer HiPace 80) \\
DP & Diaphragm pump for < 20 mbar forevacuum (KNF N 813.4 ANDC-B) \\
Power supply & 24 VDC power supply (max. 5 A during turn on) for S, QMS, TP, and \\
& DP, for instance 2×12 V 'car batteries' or mains voltage converter (e.g., \\
& Mean Well SP-240-24) \\
\hline
\end{tabular}


Table 2: Field test results for accuracy and precision of the miniRuedi analysis and the GE-MIMS method (see text). Means $(\mu)$ and standard deviations $(\sigma)$ of the residuals of the observed concentrations relative to the atmospheric equilibrium concentrations, and standard deviations of replicate air analysis results $\left(\sigma_{\text {air }}\right)$.

\begin{tabular}{cccc}
\hline Species & $\mu(\%)$ & $\sigma(\%)$ & $\sigma_{\text {air }}(\%)$ \\
\hline${ }^{4} \mathrm{He}$ & -0.5 & 2.5 & 1.9 \\
$\mathrm{~N}_{2}$ & -0.3 & 1.2 & 0.9 \\
${ }^{40} \mathrm{Ar}$ & 0.8 & 2.3 & 1.1 \\
${ }^{84} \mathrm{Kr}$ & 0.9 & 3.3 & 3.2 \\
\hline
\end{tabular}




\section{Figures}



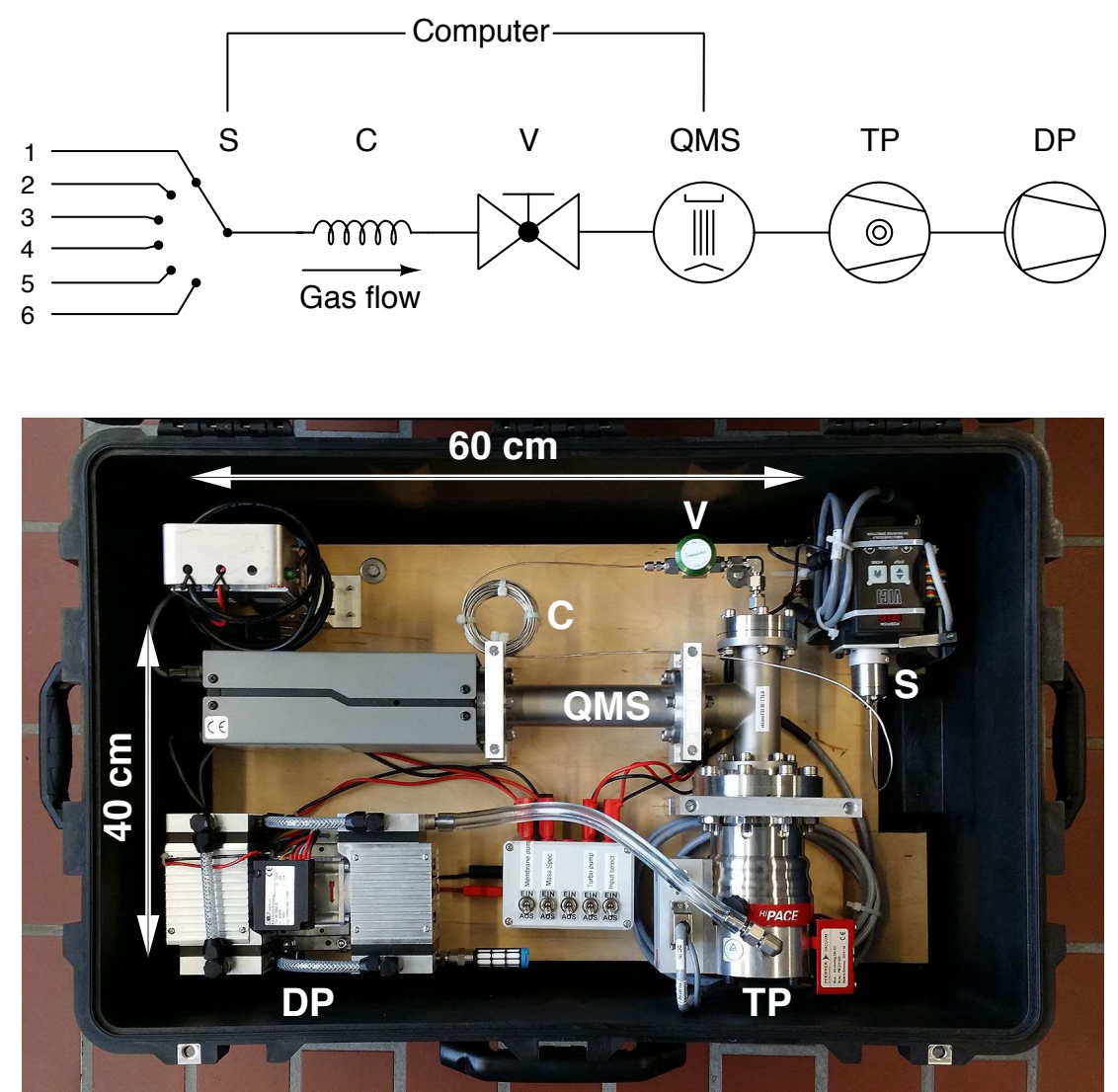

Figure 1: Schematic overview (top) and photo (bottom) of the miniRuedi mass-spectrometer system (see also Table 1): 6-port inlet selector valve (S), capillary (C), inlet valve (V), quadrupole mass spectrometer (QMS), turbomolecular pump (TP), diaphragm pump (DP). The inlet selector valve and the quadrupole mass spectrometer are controlled by a computer. The photo shows the miniRuedi mounted in a wheeled hardshell suitcase for transport and protection. 


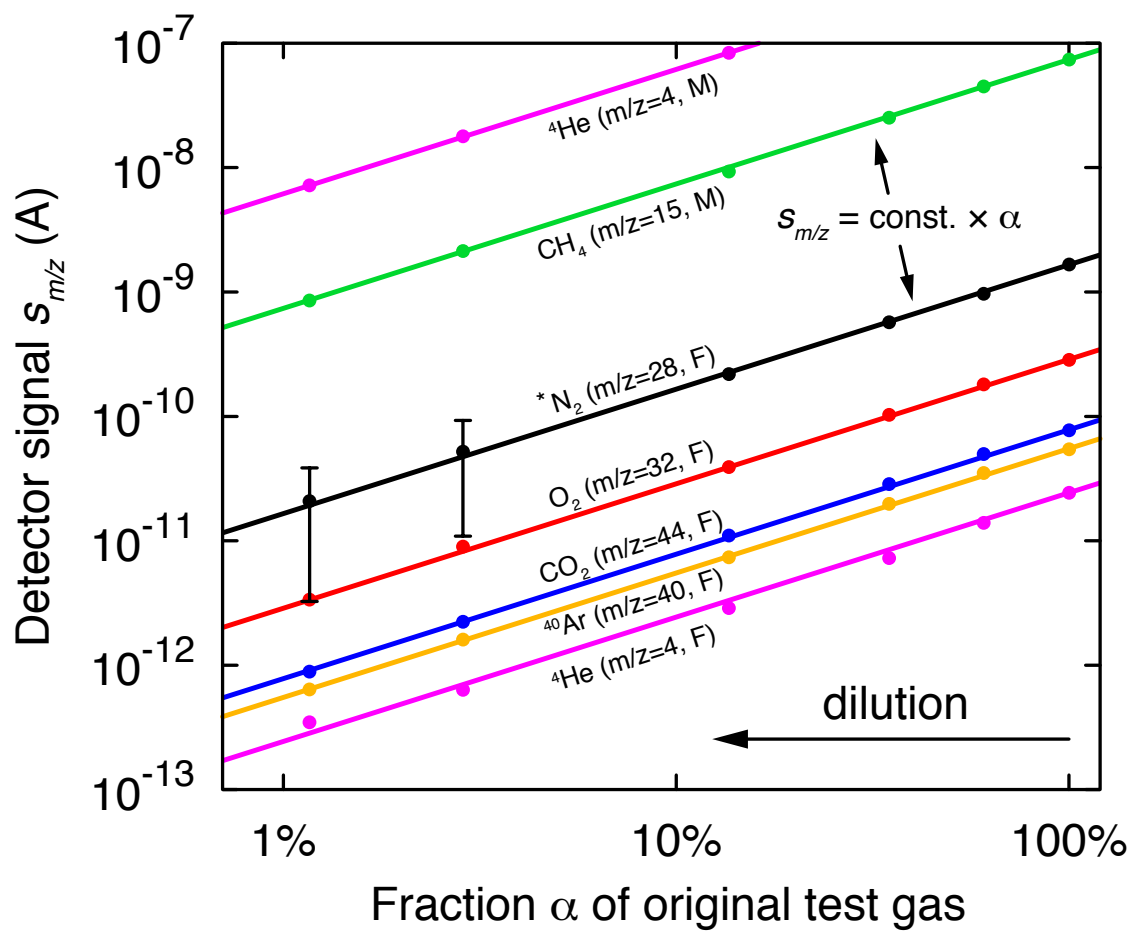

Figure 2: Peak heights $s_{m / z}$ obtained with $\mathrm{F}$ and $\mathrm{M}$ detectors from a test gas mixture (at ambient pressure) that was incrementally diluted with pure $\mathrm{N}_{2}$ to reduce the partial pressures of the various gas species (see text). The dilution is quantified as the fraction $\alpha$ of the original test gas remaining in the dilution. The $m / z=28$ peak heights corresponding to the $\mathrm{N}_{2}$ of the test gas (denoted by an asterisk, $\mathrm{N}_{2}{ }^{*}$ ) was arithmetically corrected for the contribution of the $\mathrm{N}_{2}$ added for dilution. The dots show the peak heights at the respective $m / z$ values (mean values of three replicate analyses). Error bars reflecting the standard deviations of the replicate measurements are covered by the plot symbols, except for $\mathrm{N}_{2}{ }^{*}$ error bars, which reflect the uncertainty of the dilution correction. The best-fit lines are of the form $s_{m / z}=$ const. $\times \alpha$, with $r^{2}>99.5 \%$ for all fits. 


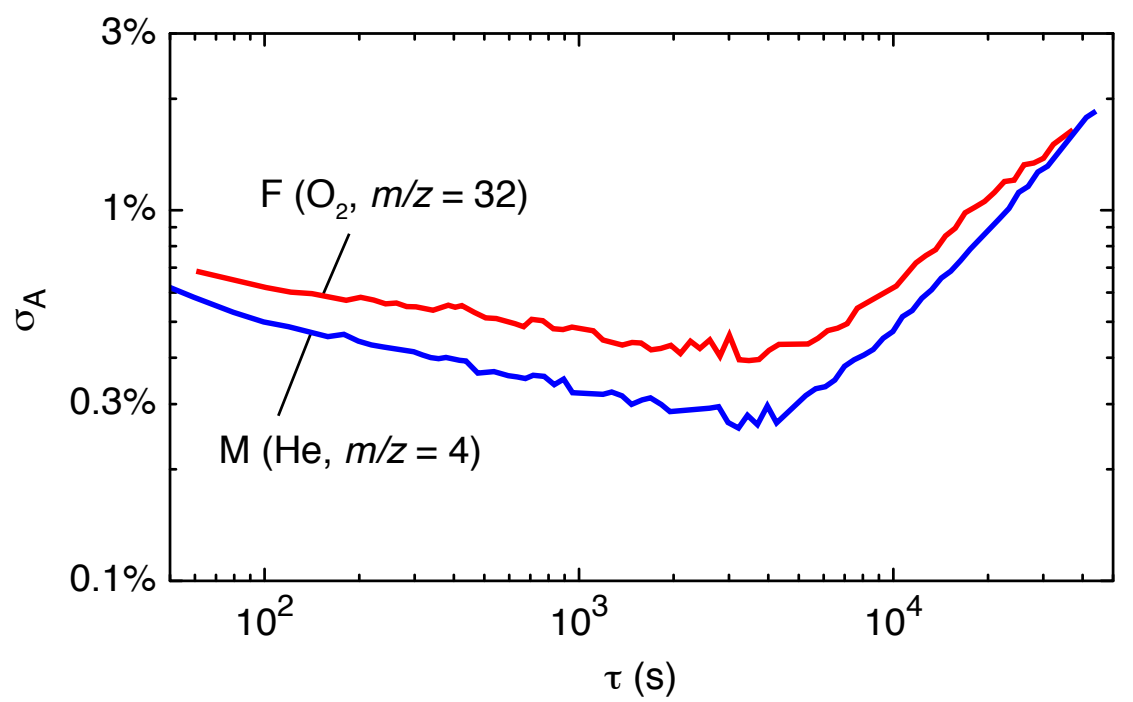

Figure 3: Relative Allan deviations $\sigma_{\mathrm{A}}$ as a function of the averaging time $\tau$ of the $\mathrm{F}$ and $\mathrm{M}$ signal readings obtained from the analysis of an air sample (see text). The instrument was operated in a laboratory with ambient temperature stabilised to $\pm 1^{\circ} \mathrm{C}$. 

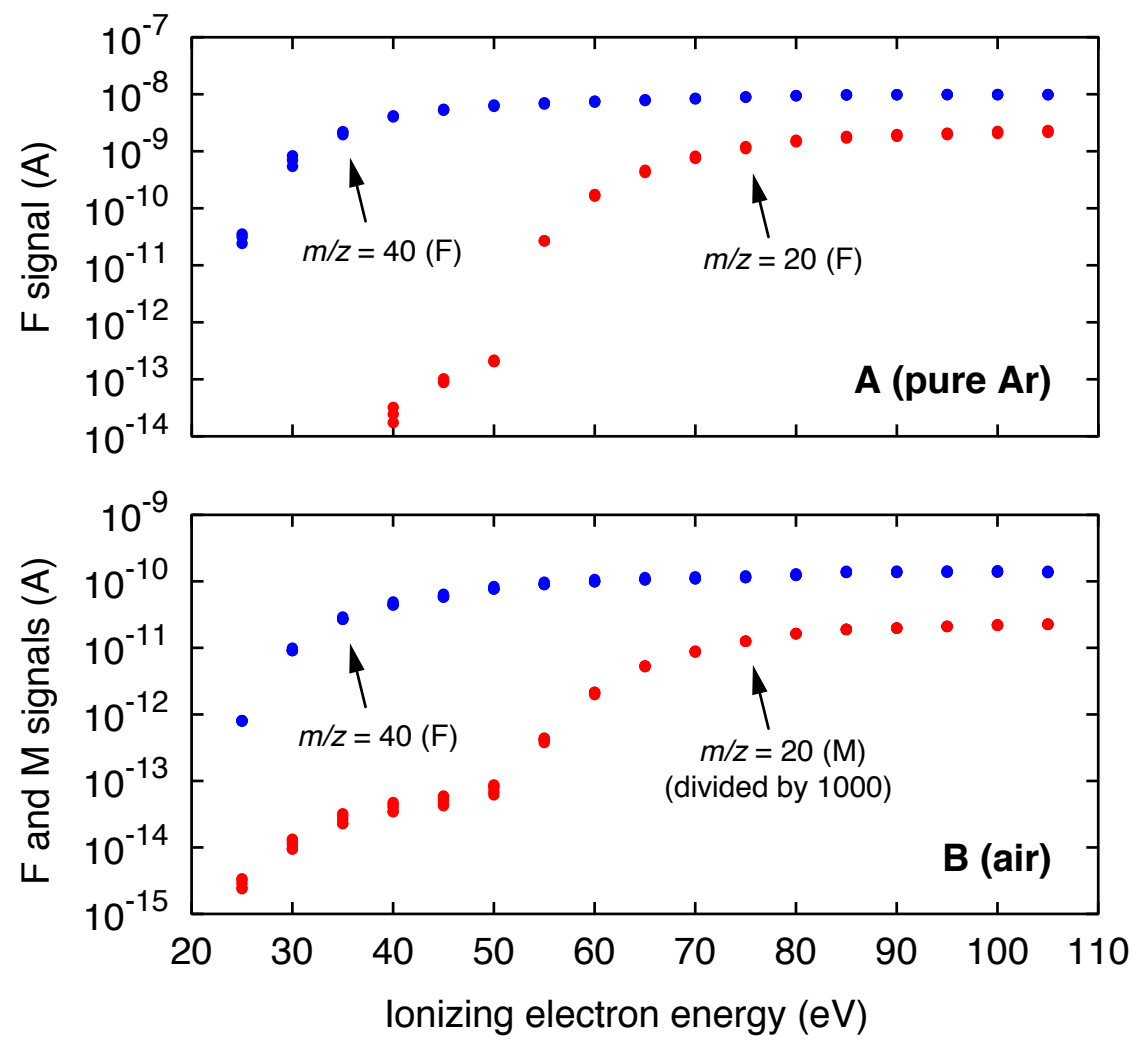

Figure 4: Peak heights at $m / z=20$ and $m / z=40$ as a function of the ionising electron energy. A: analysis of pure Ar (99.999\%) using the F detector. B: analysis of air, where peak heights at $m / z=20$ were analysed using the $\mathrm{M}$ detector and divided by 1000 to compensate for the higher sensitivity of the $\mathrm{M}$ detector relative to the $\mathrm{F}$ detector. 

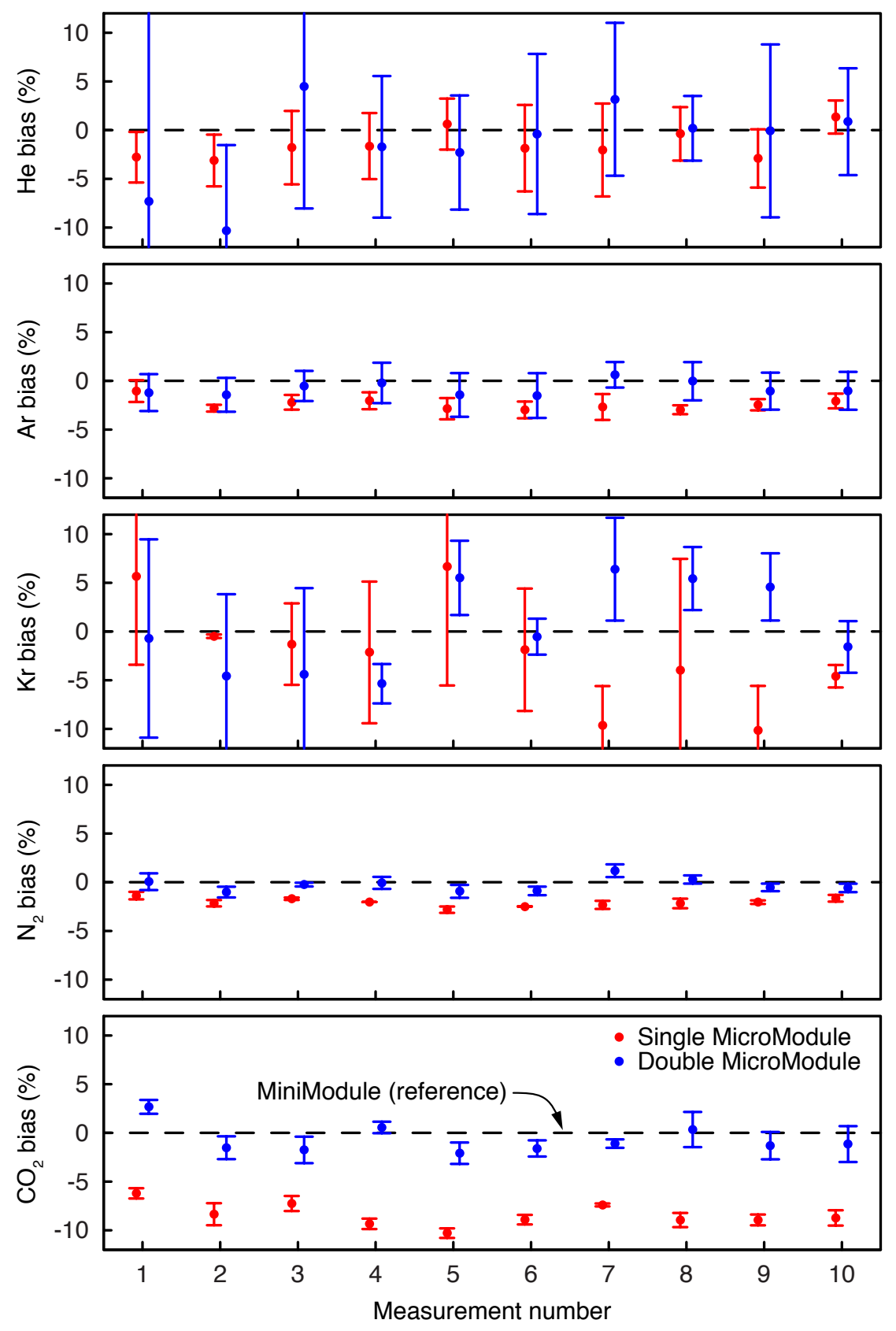

Figure 5: Bias in partial pressures obtained from GE-MIMS measurements in groundwater using miniature membrane contactors (Liqui-Cel MicroModule, type $0.5 \times 1$ / G591) relative to partial pressures in larger membrane contactors as required for the original GE-MIMS instrument ${ }^{49}$ (Liqui-Cel MiniModule, type $1.7 \times 5.5$ / G542). The miniature contactors were operated either as a single unit or as a parallel combination of two units. Groundwater was pumped through the membrane contactors, and tee branches were used to split the water flow among the membrane contactors for parallel operation of the MicroModules and the MiniModule. The error bars reflect the variability of the gas concentrations in the groundwater flow and the noise in the MS detector signals during each measurement. 


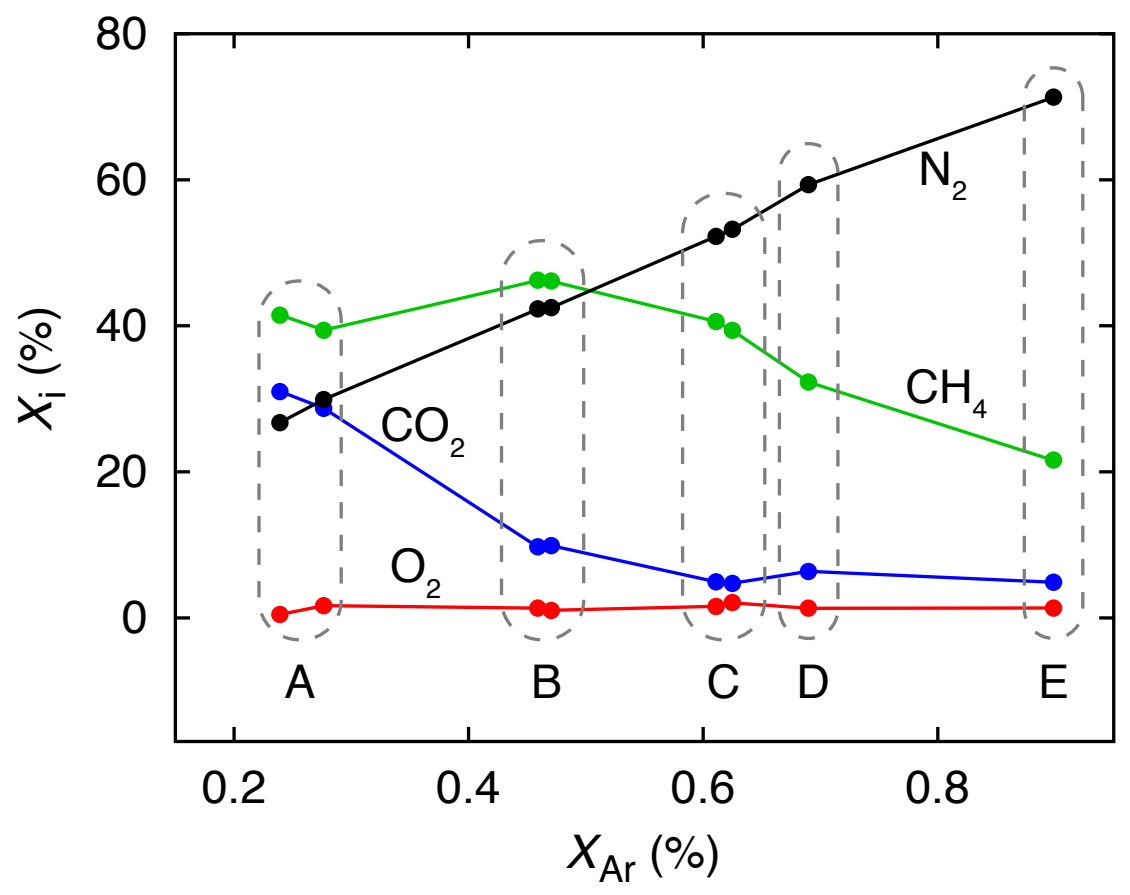

Figure 6: Soil gas composition in a covered landfill: volumetric concentrations of Ar vs. concentrations of $i=\mathrm{N}_{2}, \mathrm{O}_{2}, \mathrm{CO}_{2}, \mathrm{CH}_{4}$ in the five observations wells A-E. Replicate samples were taken in wells A, B and C. Error bars reflecting the standard errors of the measurements are covered by the plot symbols. 


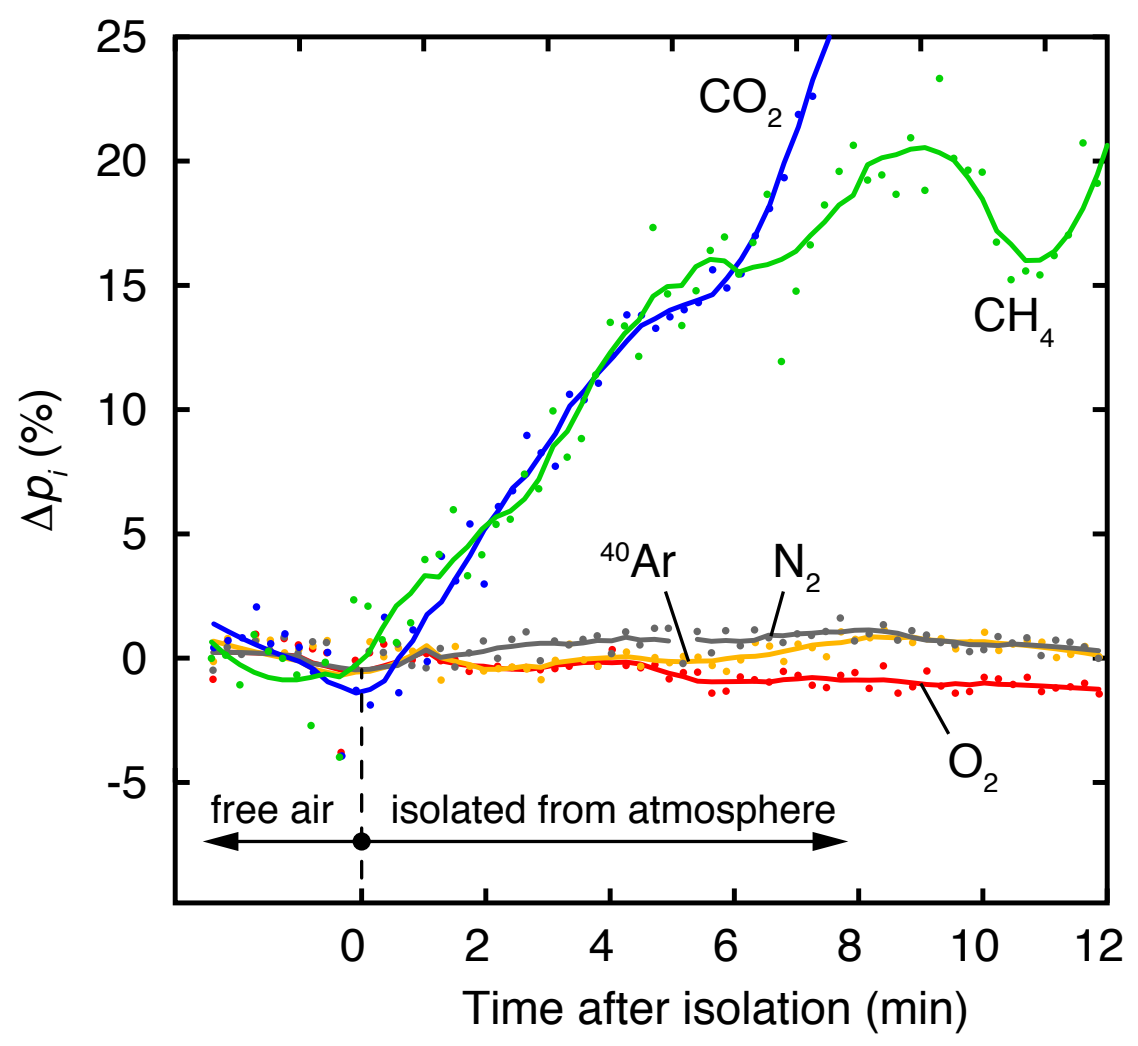

Figure 7: Gas exchange at the water surface of Lake Soppensee: changes of the partial pressures of $\mathrm{Ar}, \mathrm{N}_{2}, \mathrm{O}_{2}, \mathrm{CO}_{2}$, and $\mathrm{CH}_{4}$ in an air volume above the water surface, before and after isolating the air volume from the atmosphere ( $\Delta p_{i}$, change relative to initial partial pressures in free air). 


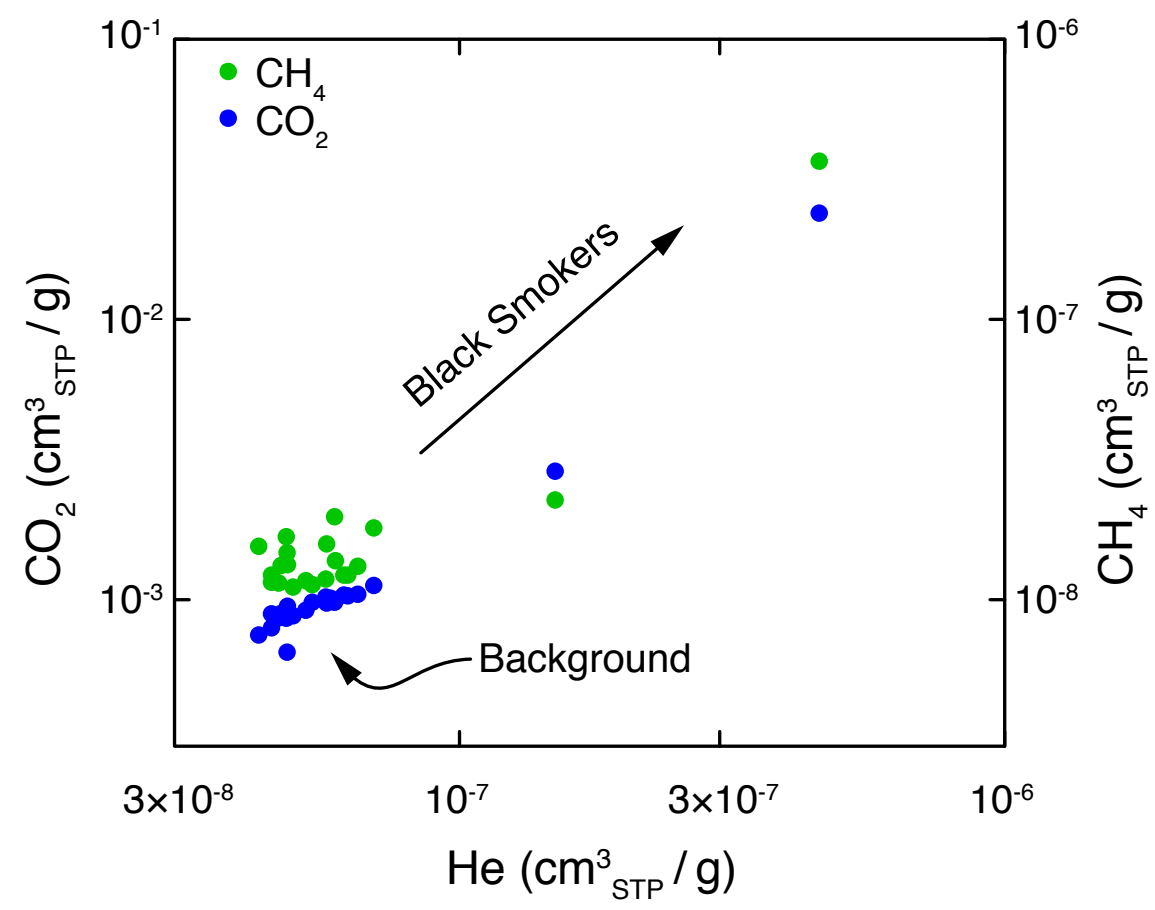

Figure 8: Screening seawater samples for hydrothermal fluids released from black smokers in the Gulf of California: ${ }^{59} \mathrm{He}, \mathrm{CO}_{2}$, and $\mathrm{CH}_{4}$ concentrations in water samples taken at water depths of up to $2 \mathrm{~km}$ (note the logarithmic axis scales). 